\title{
MECHANICAL PROPERTIES OF JOINTS CREATED BY SILVER NANOPARTICLES
}

\author{
PESINA, Z[bynek]; SOPOUSEK, J[iri] \& BURSIK, J[iri]
}

\begin{abstract}
The increase in temperature causes the decomposition of the oxide shell of silver nanoparticles. The subsequent nanoparticle aggregation effect has the potential for soldering. Silver nanoparticles were prepared by wet chemical synthesis and characterized by standard methods of electron microscopy. The substrates were made in the different temperature regimes to simulate the solder joints. In this paper microstructures and mechanical properties of joints were studied.
\end{abstract}

Key words: Ag nanoparticles, nano sintering, copper substrate, aggregation

\section{INTRODUCTION}

Materials containing toxic lead constitute health risk and serious environmental problem. On the basis of EU legislation was necessary to replace lead solders by leadfree alternatives on the date 1. 7. 2006 with the obvious aim to reduce health risks and environmental problems [1]. The most important aspects in designing a new type of solder are wettability, adequate mechanical strength, thermal and electrical conductivity and acceptable price of solder. After a decade of research it is now accepted fact that there is no universal replacement for the traditional lead-tin solder [2].

Nanoparticles of pure metals and alloys exhibit significantly different behaviour from bulk materials. Nanoparticles of pure metals show among other things the melting point depression compared to bulk materials. The main reason of the difference between behaviour of nanomaterial and bulk system is a high surface-tovolume ratio of nanomaterial [3]. The diagram in the Fig. 1 demonstrates the melting point decline in dependence on the particle diameter for $\mathrm{Sn}-\mathrm{Ag}-\mathrm{Cu}$ alloy. Fig. 2 shows the DSC curve of melting point depression for Sn nanopowder [4]. This phenomenon can be used in soldering.

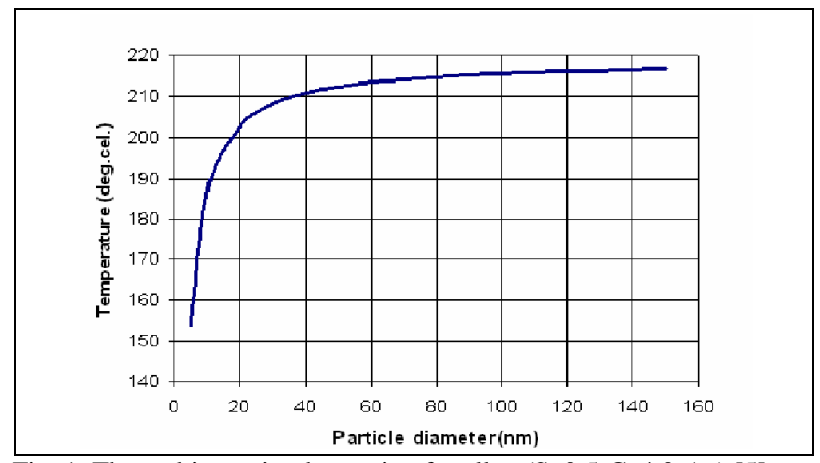

Fig. 1. The melting point depression for alloy (Sn0.5-Cu4.0-Ag) [5]

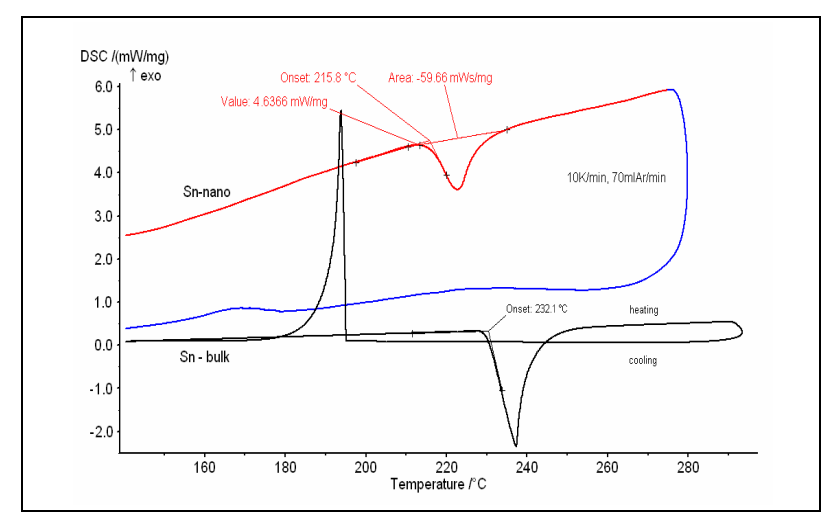

Fig. 2. The curves for Sn nanopowder (red - heating curve, blue cooling curve) and Sn bulk material (black curve). Decrease in melting point is obvious [4]

In the present paper, Ag nanoparticles were prepared by chemical wet synthesis with the aim of study their possible application in the formation of printed circuits. Mechanical properties of sintered layers at different annealing regimes were evaluated.

\section{EXPERIMENTAL}

Silver nanoparticles were prepared by thermal reaction of silver nitrate with dodecylamine in acetonnitrile. The reaction was carried out under an inert atmosphere in two steps. In the first step was prepared the complex of silver nitrate and dodecylamin and in the second step was it broken down at elevated temperature. Resulting nanoparticles were isolated as a solid phase and stored in a toluene bath. The equations of reactions are shown below.

$$
\begin{aligned}
& \mathrm{AgNO}_{3}+2 \mathrm{NH}_{2} \mathrm{C}_{12} \mathrm{H}_{25} \stackrel{\mathrm{CH}_{3} \mathrm{CN}}{\longrightarrow}\left[\mathrm{Ag}\left(\mathrm{NH}_{2} \mathrm{C}_{12} \mathrm{H}_{25}\right)_{2}\right] \mathrm{NO}_{3}(1) \\
& {\left[\mathrm{Ag}\left(\mathrm{NH}_{2} \mathrm{C}_{12} \mathrm{H}_{25}\right)_{2}\right] \mathrm{NO}_{3} \stackrel{170{ }^{\circ} \mathrm{C}, 15 \mathrm{~min}}{\longrightarrow}}
\end{aligned}
$$$$
\stackrel{170{ }^{\circ} \mathrm{C}, 15 \mathrm{~min}}{\longrightarrow} \mathrm{Ag}^{0}(\text { nano })+\mathrm{NO}_{x}+2 \mathrm{NH}_{2} \mathrm{C}_{12} \mathrm{H}_{25}
$$

Silver nanoparticles were studied by Philips CM12 STEM transmission electron microscope. The beam voltage of this device was $120 \mathrm{kV}$.

The copper rectangle sheets were used as a substrate. The shape of sheets was adapted for easy fixing to clamping jaws of universal testing machine ZWICK ROELL Z020. The sizes of the copper sheet were $45 \times 12$ $\times 1 \mathrm{~mm}$. The surface of the sheets was prepared by standard metallographic procedures including grinding, 
polishing and etching etc. The specified quantity of high concentration colloidal solution of silver nanoparticles was dropped on the surface $(12 \times 12 \mathrm{~mm})$ of the first sheet and the layer was covered with the second sheet. The $\mathrm{Cu} / \mathrm{Ag}-\mathrm{NPs} / \mathrm{Cu}$ sandwich was created. The sandwich construction was put in the furnace and annealed at various temperatures. The microstructure of resulting interlayer was characterized in the cross-sections of the substrate using a TESCAN LYRA 3 XMU FEG/SEM x FIB scanning electron microscope.

\section{RESULTS}

TEM micrographs of Ag-NPs showed the presence of single nanoparticles with diameter below $10 \mathrm{~nm}$ with a narrow size distribution and there were found occasional presence of little clusters (Fig.3). The quantity of nanoparticles was sufficient for the joints preparation.

Fig. 3. TEM micrograph of silver nanoparticles

High Resolution TEM technique utilizing interference phase contrast is able to image of single atoms arranged in crystal lattice of material. HR-TEM micrograph showed very regular FCC lattice of the silver particle (Fig. 4). The measured lattice parameter $(\mathrm{a}=$ $0.424 \mathrm{~nm}$ ) was in a good correspond to the tabulated value $(\mathrm{a}=0.40862 \mathrm{~nm})$.

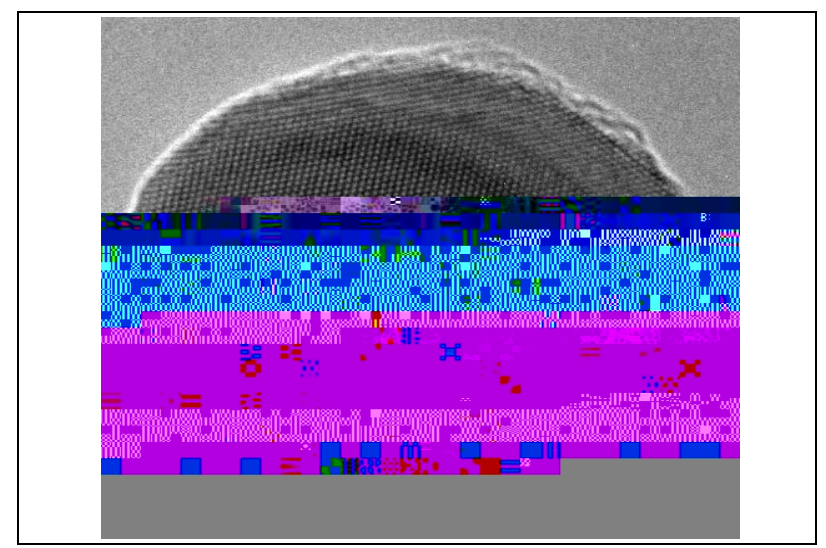

Fig. 4. HR-TEM micrograph of single nanoparticle

The shear strength was measured on the samples, which were annealed at the different temperature regimes $\left(150{ }^{\circ} \mathrm{C}, 200{ }^{\circ} \mathrm{C}, 220{ }^{\circ} \mathrm{C}\right.$ and $\left.350{ }^{\circ} \mathrm{C}\right)$. The sandwiches were heated up inside the furnace from the room temperature at $15^{\circ} \mathrm{C} / \mathrm{min}$ rate. The obtained curves of the shear strength are shown in Fig. 5 - Fig.7.

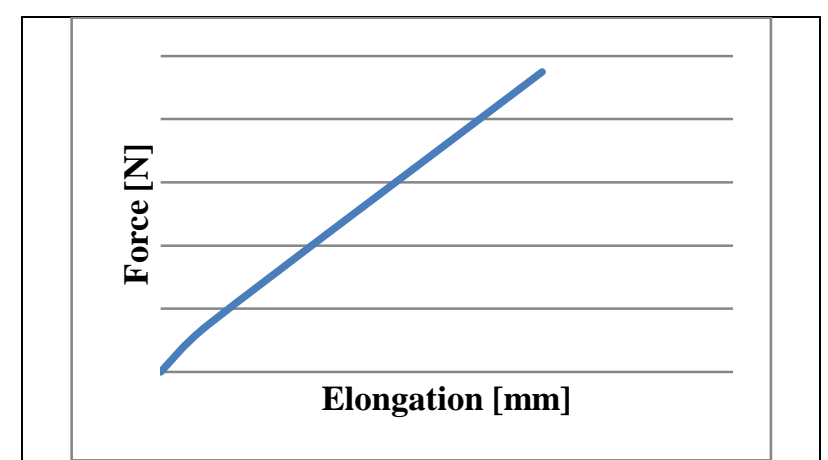

Fig. 5. The curve after shear test. $\mathrm{T}=200^{\circ} \mathrm{C}, \mathrm{t}=30 \mathrm{~min}$

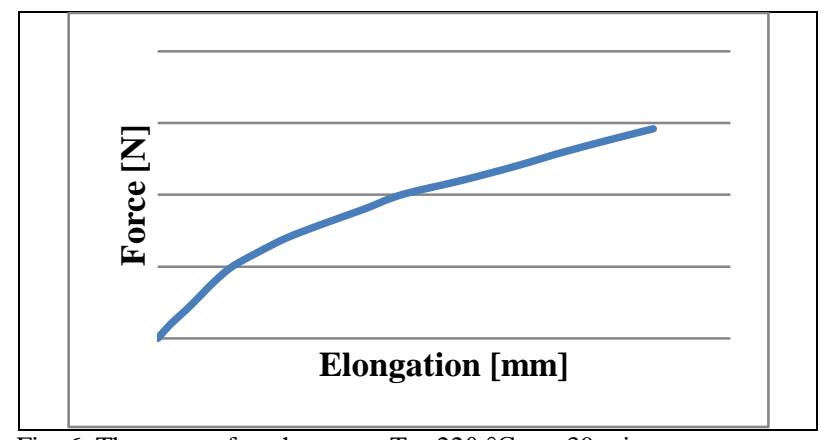

Fig. 6 . The curve after shear test. $\mathrm{T}=220^{\circ} \mathrm{C}, \mathrm{t}=30 \mathrm{~min}$

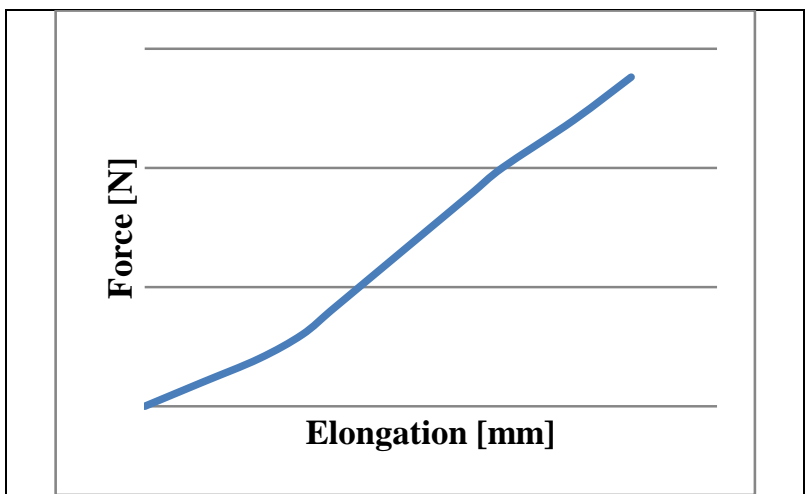

Fig. 7. The curve after shear test. $\mathrm{T}=350^{\circ} \mathrm{C}, \mathrm{t}=30 \mathrm{~min}$

\begin{tabular}{|c|c|c|}
\hline $\mathbf{T}(\tilde{\mathbf{A}} \mathbf{C})$ & $\mathbf{R}_{\mathbf{m}}(\mathbf{M P a})$ & $\mathbf{E}(\mathbf{M P a})$ \\
\hline 150 & - & - \\
\hline 200 & 3 & 10874 \\
\hline 220 & 13 & 11865 \\
\hline 350 & 6 & 12450 \\
\hline
\end{tabular}

Tab. 1. The results of the mechanical parameters measured for the different annealing temperatures ( $\mathrm{E}$.. modulus of elasticity, $\mathrm{R}_{\mathrm{m}}$.. shear strength of joint)

The second shear strength measurements were carried out at the constant temperature sintering. The shear strength was measured on the samples, which were annealed at the temperature $350{ }^{\circ} \mathrm{C}$. This value is the limitary temperature because of danger damage of substrate used in electronic industry. Silver nanoparticles were deposited on the surface of sheet as a colloidal suspension. Each sample was tested under variable load in the contact of nanoparticles with the copper sheets. Samples were kept in the furnace for 30 minutes duration to perform perfect nanosintering process. The construction of the sandwich joint is shown in Fig. 8. The curves of the shear strength for the different load are shown in Fig. 9 - Fig. 11. 


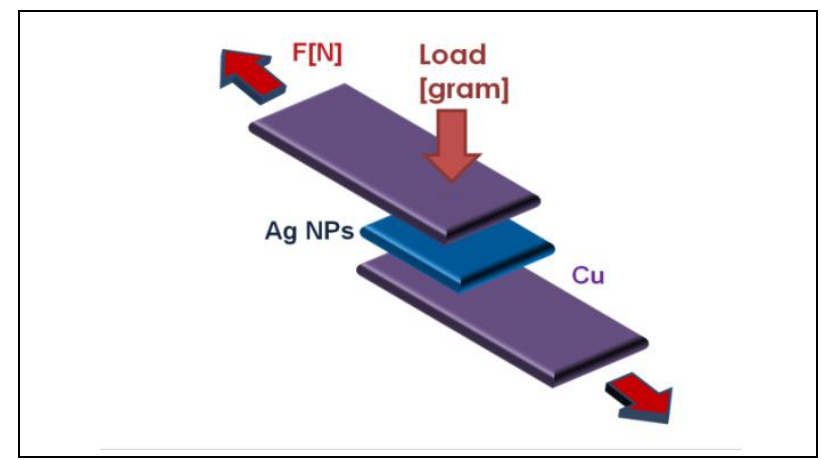

Fig. 8. The construction of sandwich joint

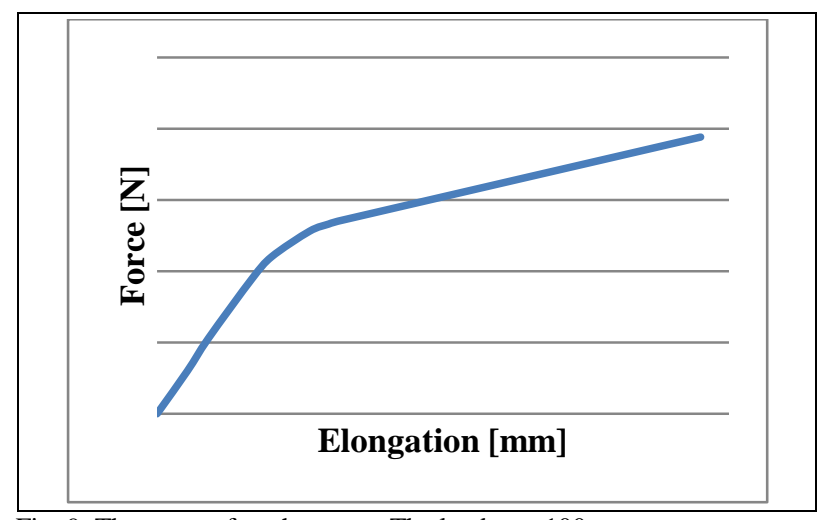

Fig. 9. The curve after shear test. The load was $100 \mathrm{~g}$

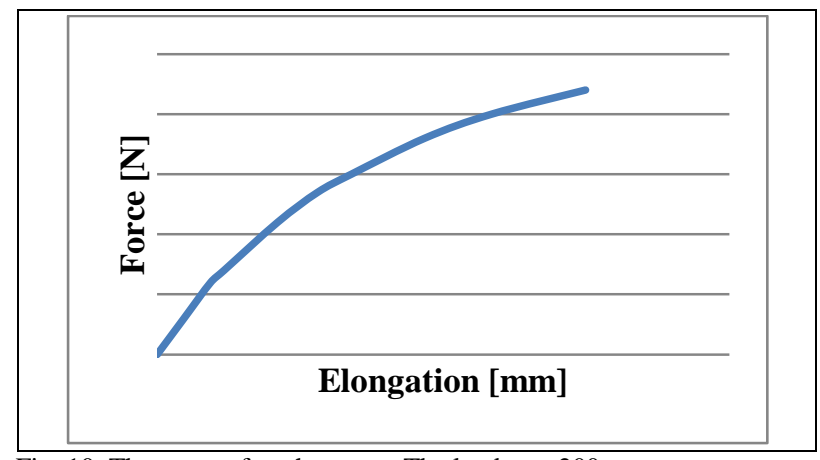

Fig. 10. The curve after shear test. The load was $200 \mathrm{~g}$

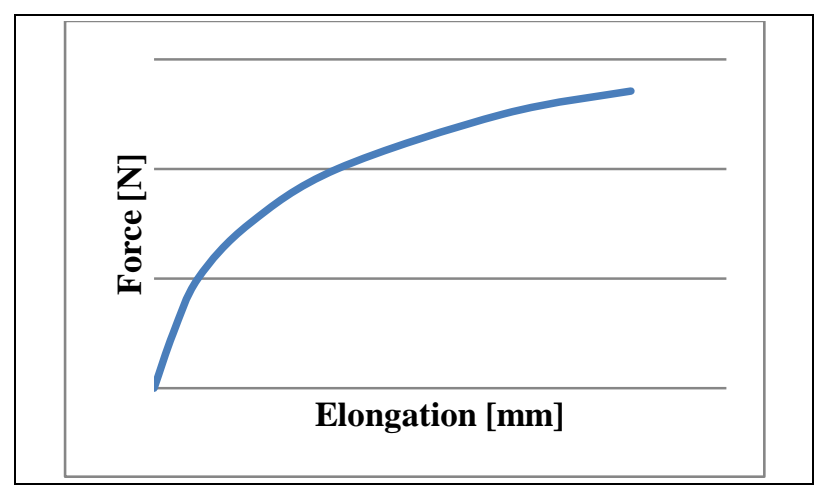

Fig. 11. The curve after shear test. The load was $500 \mathrm{~g}$

\begin{tabular}{|c|c|c|}
\hline Load [gram] & $\mathbf{R}_{\mathbf{m}}(\mathbf{M P a})$ & $\mathbf{E}$ (MPa) \\
\hline 100 & 16 & 11991 \\
\hline 200 & 18 & 15151 \\
\hline 500 & 23 & 19993 \\
\hline
\end{tabular}

Tab. 2. The results of the mechanical parameters measured for the different load. (E .. modulus of elasticity, $R_{m}$.. shear strength of joint)

SEM micrographs of the $\mathrm{Cu} / \mathrm{Ag}-\mathrm{NPs} / \mathrm{Cu}$ sandwiches are shown in Fig. 12 and Fig. 13. It is obvious that agglomeration of silver nanoparticles between the copper sheets is occurred. Silver nanoparticles agglomeration is main mechanism for creating the strength joint. The SEM microscopy method indicated the presence of pores in all samples.

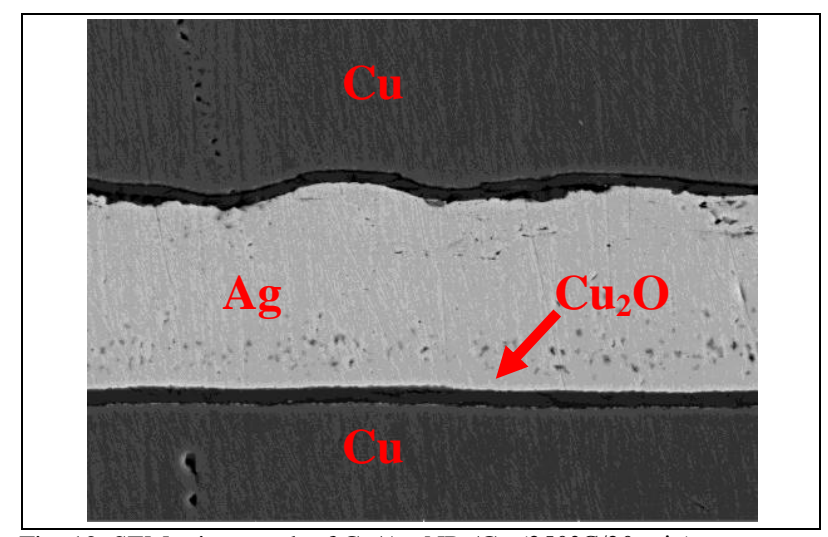

Fig. 12. SEM micrograph of $\mathrm{Cu} / \mathrm{Ag}-\mathrm{NPs} / \mathrm{Cu}\left(350^{\circ} \mathrm{C} / 30 \mathrm{~min}\right)$

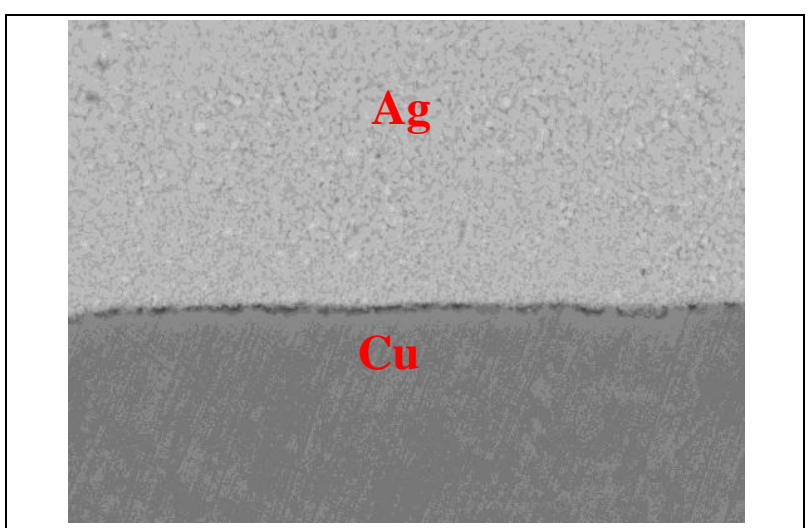

Fig. 13. SEM micrograph of $\mathrm{Cu} / \mathrm{Ag}-\mathrm{NPs} / \mathrm{Cu}\left(200^{\circ} \mathrm{C} / 30 \mathrm{~min}\right)$

The investigation of the interface between copper substrate and nanosintered silver was performed by Energy-Dispersive X-ray (EDX) analysis which is the fixture of SEM system. EDX examination was carried out across the interlayer in order to determine the elements content.

There was a presence of oxygen which causes formation of $\mathrm{Cu}_{2} \mathrm{O}$ interlayer. The results of thicknesses of the $\mathrm{Cu}_{2} \mathrm{O}$ interlayer by way of EDX study for sandwiches made at various temperatures are shown in Fig. 14 and Fig. 15. The measurement of the interlayer in the samples annealed at different temperature reveal that kinetics of oxide is close to a parabolic growth.

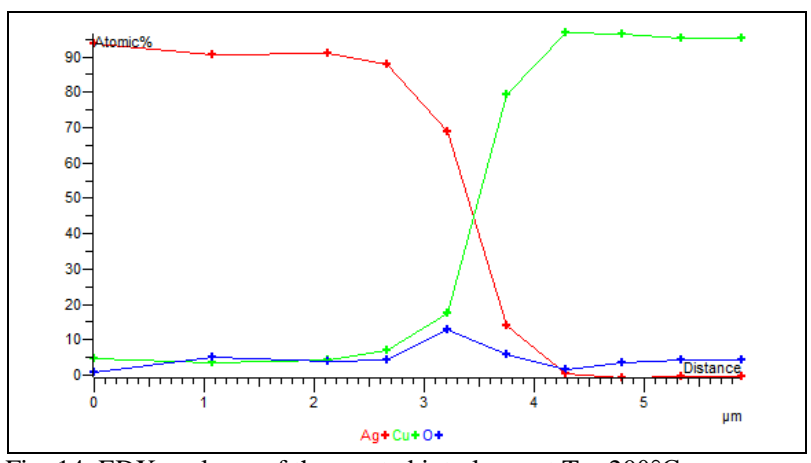

Fig. 14. EDX analyses of the created interlayer at $\mathrm{T}=200^{\circ} \mathrm{C}$ 


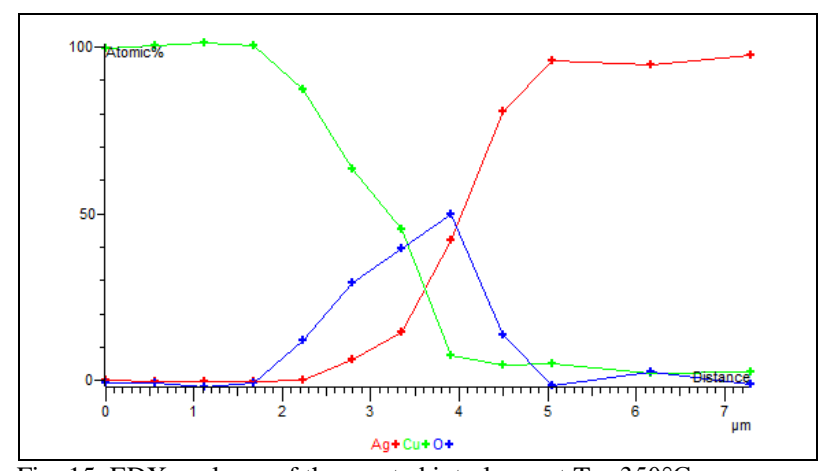

Fig. 15. EDX analyses of the created interlayer at $\mathrm{T}=350^{\circ} \mathrm{C}$

\section{DISCUSSION}

Dodecylamine used in wet synthesis forms a protective shell on the surface of nanoparticles. The increased temperature causes the break-up of this shell and its substitute by oxide layer. The newly created layer around the single nanoparticles requires the next growth of temperature to decomposition of oxide shell. After this break-up the sintering effect of single nanoparticles step is launched.

Fig. 12 and Fig. 13 demonstrate the microstructure of the silver interlayer, which was formed by the low temperature sintering process. The compactness of the silver interlayer is mainly dependent on height of annealing temperature and annealing time and the presence of the pores. The microstructure in Fig. 13 is characterized by the presence of original powder structure. After the decomposition of the oxide shell covering the individual silver nanoparticles, nanosintering process was initiated but the annealing temperature was not high enough to obtain the uniform sintered layer without the presence of the singular sliver nanoparticles. Fig. 12 shows a micrograph of the sintered layer with the sporadic presence of pores. There is a presence of visible interlayer between the copper sheets and the silver layer. EDX analysis performed through the interlayer exposed the high proportion of oxygen. The thickness of the firm $\mathrm{Cu}_{2} \mathrm{O}$ interlayer is growing with the increasing of the annealing temperature because of higher diffusion rate of atmospheric oxygen among individual pores.

The shear strength of annealed sample at $150{ }^{\circ} \mathrm{C}$ was undetectable because of low sintering temperature. A similar situation was found out in the sample annealed at $200{ }^{\circ} \mathrm{C}$, where the value of the shear strength was low because of running intermediate stage of sintering. A significant increase of shear strength was observed for the sample annealed at $220^{\circ} \mathrm{C}$. The perfect nanosintering process and minimal thickness of the $\mathrm{Cu}_{2} \mathrm{O}$ interlayer caused the sharply increase of the shear strength value. In contrast, the significant decrease of the shear strength is seen for sample annealed at $350{ }^{\circ} \mathrm{C}$. This phenomenon is caused by the huge thickness of $\mathrm{Cu}_{2} \mathrm{O}$ interlayer, present of pores and organic phases.

The resulting sandwich construction $\mathrm{Cu} / \mathrm{Ag} \mathrm{NPs} / \mathrm{Cu}$ created at various loads showed the good resistance to mechanical failure. The increasing load causes the rise of the mechanical parameters of the joints. Expect the above mentioned parameters the preparation of sheets affects the resulting strength. Fig. 16 shows the rough sample. Resulting joint strength decreased twice in comparison to the polished surface of the sample.

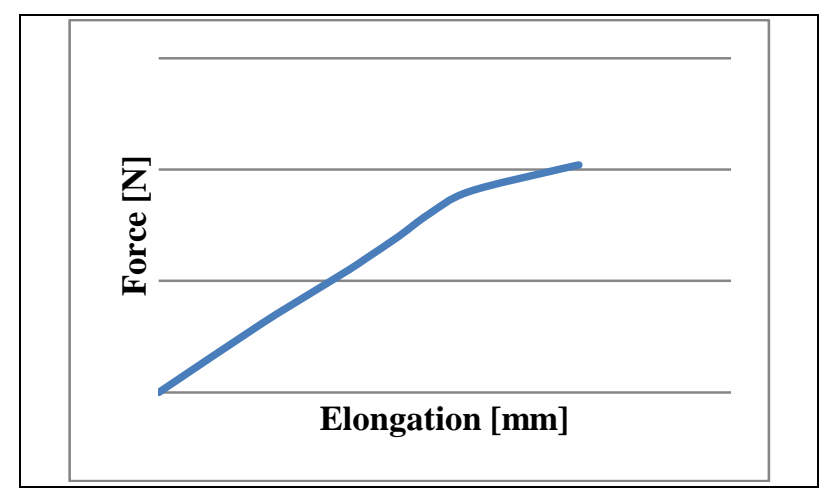

Fig. 16. The curve after shear test. The load was 200 g. The sample was rough and unpolished

\section{CONCLUSIONS}

In this article mechanical properties of joints made by the silver nanoparticles were measured.

The experimental results performed in previous works using thermal analysis methods (DTA, TG) showed the optimum sintering temperature in the range of $(220-230){ }^{\circ} \mathrm{C}$. The sintering temperature near $220{ }^{\circ} \mathrm{C}$ and the time duration about 30 minutes at this temperature provided very good mechanical characteristics. The annealing temperature in the range of $(220-350){ }^{\circ} \mathrm{C}$ is approximately $(0.23-0.36) \mathrm{T}_{\mathrm{m}}$ of bulk silver. Silver nanosintering process seems to be a promising alternative to the bulk alloys in lead-free soldering.

The attention in the future works will be focused on the optimization of the deposition silver nanoparticles on the copper substrate and to minimize quantity of pores created at production of nanoparticles. The next aim is to ensure a minimum thickness of $\mathrm{Cu}_{2} \mathrm{O}$ which negatively affected the properties of joints.

\section{ACKNOWLEDGEMENTS}

Financial support from the Czech Science Foundation (grant No. 106/09/H035) and Ministry of Education, Youth and Sports of the Czech Republic (CEITEC MU cz.1.05/1.1.00/02.0068) is gratefully acknowledged.

\section{REFERENCES}

[1] Yamamoto, T. \& Tsubone, K. (2007) Assembly technology using lead-free solder. Fujitsu Sci. Tech. J.,Vol.43, pp. 50-58, ISSN 0016-2523

[2] Drapala, J., Urbanikova, Z., Zlatohlavek, P. \& Vrestal, J. (2005) Materialy pro bezolovnate pajky. ISBN $80-86840-13$, pp. 1-9, Tanger spol. s.r.o., Ostrava

[3] Qi, W.H. \& Wang, M.P. (2002) Size effect on the cohesive energy of nanoparticle. Journal of Materials Science Letters, Vol.21, p.1743-1745, ISSN: 1573-4811

[4] Broz, P., Sopousek, J. \& Vrestal, J. (2009). On the stability of Ag, $\mathrm{Cu}$ and $\mathrm{Sn}$ nanoparticles. CALPHAD XXXVIII, Prague 17-22.5. 2009, pp. 118-118

[5] Liu, J. (2007) Development of Nano Lead Free Solders, Challenges and Future Research Topics, MP0602, Joint Working Group meeting, Brno 